\title{
Tofacitinib, an Oral Janus Kinase Inhibitor, in Active Ulcerative Colitis
}

\author{
William J. Sandborn, M.D., Subrata Ghosh, M.D., Julian Panes, M.D., \\ Ivana Vranic, Ph.D., Chinyu Su, M.D., Samantha Rousell, M.Sc., \\ and Wojciech Niezychowski, M.D., for the Study A3921063 Investigators
}

ABSTRACT

From the University of California San Diego, La Jolla (W.J.S.); University of Calgary, Calgary, Alberta, Canada (S.G.); Hospital Clinic de Barcelona, Institut d'Investigacions Biomèdiques August $\mathrm{Pi}$ i Sunyer, Centro de Investigación Biomédica en Red de Enfermedades Hepáticas y Digestivas, Barcelona (J.P.); and Pfizer, Sandwich, United Kingdom (I.V., S.R.), and Collegeville, PA (C.S., W.N.). Address reprint requests to $\mathrm{Dr}$. Sandborn at the Division of Gastroenterology, University of California San Diego, 9500 Gilman Dr., La Jolla, CA 92093 0956, or atwsandborn@ucsd.edu.

N Engl J Med 2012;367:616-24. DOI: 10.1056/NEJMoal112168 Copyright @ 2012 Massachusetts Medical Society.

\section{BACKGROUND}

Ulcerative colitis is a chronic inflammatory disease of the colon for which current treatments are not universally effective. One additional treatment may be tofacitinib (CP-690,550), an oral inhibitor of Janus kinases 1, 2, and 3 with in vitro functional specificity for kinases 1 and 3 over kinase 2, which is expected to block signaling involving gamma chain-containing cytokines including interleukins 2, 4, 7, 9, 15, and 21. These cytokines are integral to lymphocyte activation, function, and proliferation.

\section{METHODS}

In a double-blind, placebo-controlled, phase 2 trial, we evaluated the efficacy of tofacitinib in 194 adults with moderately to severely active ulcerative colitis. Patients were randomly assigned to receive tofacitinib at a dose of $0.5 \mathrm{mg}, 3 \mathrm{mg}, 10 \mathrm{mg}$, or $15 \mathrm{mg}$ or placebo twice daily for 8 weeks. The primary outcome was a clinical response at 8 weeks, defined as an absolute decrease from baseline in the score on the Mayo scoring system for assessment of ulcerative colitis activity (possible score, 0 to 12 , with higher scores indicating more severe disease) of 3 or more and a relative decrease from baseline of $30 \%$ or more with an accompanying decrease in the rectal bleeding subscore of 1 point or more or an absolute rectal bleeding subscore of 0 or 1 .

\section{RESULTS}

The primary outcome, clinical response at 8 weeks, occurred in $32 \%, 48 \%, 61 \%$, and $78 \%$ of patients receiving tofacitinib at a dose of $0.5 \mathrm{mg}(\mathrm{P}=0.39), 3 \mathrm{mg}(\mathrm{P}=0.55)$, $10 \mathrm{mg}(\mathrm{P}=0.10)$, and $15 \mathrm{mg}(\mathrm{P}<0.001)$, respectively, as compared with $42 \%$ of patients receiving placebo. Clinical remission (defined as a Mayo score $\leq 2$, with no subscore $>1$ ) at 8 weeks occurred in 13\%, 33\%, 48\%, and $41 \%$ of patients receiving tofacitinib at a dose of $0.5 \mathrm{mg}(\mathrm{P}=0.76), 3 \mathrm{mg}(\mathrm{P}=0.01), 10 \mathrm{mg}(\mathrm{P}<0.001)$, and $15 \mathrm{mg}$ $(\mathrm{P}<0.001)$, respectively, as compared with $10 \%$ of patients receiving placebo. There was a dose-dependent increase in both low-density and high-density lipoprotein cholesterol. Three patients treated with tofacitinib had an absolute neutrophil count of less than 1500.

\section{CONCLUSIONS}

Patients with moderately to severely active ulcerative colitis treated with tofacitinib were more likely to have clinical response and remission than those receiving placebo. (Funded by Pfizer; ClinicalTrials.gov number, NCT00787202.) 
LCERATIVE COLITIS IS A CHRONIC INflammatory disease of the colon. ${ }^{1,2} \mathrm{~Pa}$ tients have intermittent disease flares interspersed with periods of remission. ${ }^{3}$ Ulcerative colitis is treated with mesalamine, glucocorticoids, azathioprine, and anti-tumor necrosis factor (TNF) agents (infliximab and adalimumab). ${ }^{4-6}$ These agents are not universally effective, and some have been associated with serious toxic effects. ${ }^{7}$ Additional treatments are needed.

Tofacitinib (CP-690,550) is a selective oral inhibitor of the Janus kinase (JAK) family of kinases, including JAK 1 and JAK3, a tyrosine kinase that mediates signal-transduction activity involving the common gamma chain of the surface receptors for multiple cytokines, including interleukins 2, 4, 7, 9, 15, and 21.8,9 These cytokines are integral to lymphocyte activation, function, and proliferation. In vitro, tofacitinib inhibits interleukin-2-dependent differentiation of type 2 and type 17 helper $\mathrm{T}$ cells as well as lipopolysaccharideinduced innate immune responses. ${ }^{10}$ In addition, the inhibition of JAK1 attenuates signaling by proinflammatory cytokines, such as interleukin- 6 and interferon- $\gamma \cdot{ }^{11}$ At high exposure to tofacitinib in preclinical models, inhibition of erythropoietin signaling may occur by means of inhibition of JAK2 signaling. ${ }^{11}$

Blockade of a common signaling molecule used by six important cytokines should result in suppression of both $\mathrm{T}$ and $\mathrm{B}$ cells while maintaining regulatory T-cell function. ${ }^{8-10,12}$ Although the importance of the JAK family in the pathogenesis of ulcerative colitis is unclear, tofacitinib has shown efficacy for prevention of organ allograft rejection ${ }^{13,14}$ and in the treatment of rheumatoid arthritis $^{15-18}$ and psoriasis. ${ }^{19,20}$ We designed an 8-week, placebo-controlled, dose-finding trial of tofacitinib in patients with moderately or severely active ulcerative colitis.

\section{METHODS}

\section{STUDY CONDUCT}

The sponsor, Pfizer, helped to design the study and analyze the data. The principal academic investigator also designed the study and wrote the first draft of the manuscript. Data were collected by a contract research organization (Kendle International). All authors vouch for the veracity and completeness of the data and data analyses and for the fidelity of this report to the protocol (available with the full text of this article at NEJM.org), approved the final version, and made the decision to submit the manuscript for publication. All authors have confidentiality agreements with Pfizer.

The study was approved by the institutional review board or independent ethics committee for each center. All patients provided written informed consent.

\section{STUDY PATIENTS}

Our 8-week multicenter, randomized, double-blind, placebo-controlled trial was conducted at 51 centers in 17 countries (Belgium, Brazil, Chile, Czech Republic, Denmark, France, Hungary, Israel, Italy, Mexico, the Netherlands, Poland, Slovakia, South Africa, Spain, Sweden, and the United Kingdom) from January 2009 through September 2010.

Two eligibility criteria were an age of at least 18 years and a confirmed diagnosis of ulcerative colitis for at least 3 months. The other two eligibility criteria relate to the Mayo scoring system for assessment of ulcerative colitis activity (in which scores range from 0 to 12 and higher scores indicate more severe disease), ${ }^{21}$ a scale composed of four subscores (for stool frequency, rectal bleeding, endoscopic findings, and Physician's Global Assessment; scores on each can range from 0 to 3). These criteria were a score of 6 to 12 on the Mayo scale and moderately or severely active disease on sigmoidoscopy (i.e., a Mayo endoscopic findings subscore of 2 or 3, respectively). Patients could receive oral mesalamine or oral prednisone at a stable dose of $30 \mathrm{mg}$ or less per day. Exclusion criteria are given in the Supplementary Appendix (available at NEJM.org).

\section{STUDY DESIGN}

Patients were randomly assigned, in a 2:2:2:3:3 ratio, to receive oral tofacitinib (CP-690,550) (Pfizer) at a dose of $0.5 \mathrm{mg}, 3 \mathrm{mg}, 10 \mathrm{mg}$, or $15 \mathrm{mg}$ or placebo, administered twice daily. Patients were treated for 8 weeks and followed for 4 weeks afterward (through 12 weeks). No data on clinical outcomes or adverse events were collected beyond 12 weeks. Randomization was performed centrally, according to a computer-generated randomization schedule, with the use of permuted blocks balanced within each randomization stratum (e.g., previous exposure to anti-TNF therapy: yes or no). Oral mesalamine, if in use, was permitted at stable 
doses; doses of oral glucocorticoids could not be increased, but tapering was permitted.

FOLLOW-UP, EFFICACY, AND SAFETY EVALUATIONS

The Mayo score was determined at baseline and 8 weeks. A partial Mayo score (based on three of the four questions [lacking the endoscopic findings subscore], for a range of 0 to 9 ), was determined at $0,2,4$, and 8 weeks. Colonoscopy or flexible sigmoidoscopy was performed at baseline and again at 8 weeks. Clinical response was defined as a decrease from baseline in the total Mayo score - defined as an absolute decrease by at least 3 points and a relative decrease by at least $30 \%$ - with an accompanying decrease in the rectal bleeding subscore of at least 1 point or an absolute rectal bleeding subscore of 0 or $1 .^{22,23}$ Clinical remission was defined as a total Mayo score of 0 to 2, with no individual subscore exceeding 1. ${ }^{22,23}$ Endoscopic response was defined as a decrease from baseline in the endoscopy subscore by at least 1 , and endoscopic remission was defined as an endoscopy subscore of $0 .^{22,23}$ The health-related quality of life was measured with the use of the Inflammatory Bowel Disease Questionnaire (with scores ranging from 0 to 224 points and scores of 170 points or more indicating clinically inactive disease). ${ }^{24}$

Adverse events and use of medications concomitantly with tofacitinib or placebo were recorded through 12 weeks. Blood samples were collected at each visit for hematologic and chemical analyses; at 0, 4, and 8 weeks for measuring C-reactive protein (CRP) concentration; and at 0,8 , and 12 weeks for lipid profiling. Stool samples were collected at each visit to ascertain fecal calprotectin concentrations (at Quintiles Laboratories; lower limit of detection, $28 \mathrm{mg}$ per kilogram of stool). Fecal calprotectin is a biomarker for neutrophil migration into the gastrointestinal tract and intestinal inflammation.

\section{STATISTICAL ANALYSIS}

The primary efficacy end point was a clinical response at 8 weeks. Secondary efficacy end points included clinical remission at 8 weeks; endoscopic response at 8 weeks; endoscopic remission at 8 weeks; change from baseline in the partial Mayo score at 2, 4, and 8 weeks; change from baseline in the total Mayo score at 8 weeks; change from baseline in the CRP concentration at 4 and 8 weeks; and the change from baseline in the fecal calpro- tectin concentration at 2, 4, and 8 weeks. The changes from baseline in low-density lipoprotein (LDL) and high-density lipoprotein (HDL) cholesterol concentrations and serum creatinine concentrations at 8 and 12 weeks were also determined.

\section{Prespecified Analyses}

The analysis of the primary end point of clinical response at 8 weeks and the secondary end points of clinical remission, endoscopic response, and endoscopic remission - all at 8 weeks - was performed by means of a maximum-effective-dose $\left(\mathrm{E}_{\mathrm{MAX}}\right)$ model (or an alternative if appropriate) with treatment group as a factor and a term included for prior anti-TNF therapy. Patients with data missing for reasons other than insufficient response to therapy or an adverse event related to ulcerative colitis were excluded from the analysis.

The change from baseline in the partial Mayo score at weeks 2, 4, and 8 and in the total Mayo score at 8 weeks were analyzed by means of an analysis-of-covariance model with terms for study treatment, baseline Mayo scores, and prior antiTNF treatment based on last-observation-carriedforward imputation. CRP concentrations and fecal calprotectin concentrations were natural log-transformed, and the change from baseline at 2 weeks (for fecal calprotectin only) and 4 and 8 weeks were analyzed with the use of an analysisof-variance model with last-observation-carriedforward imputation. The changes from baseline in serum creatinine concentrations at 2, 4, 8, and 12 weeks and in LDL and HDL cholesterol concentrations at 8 and 12 weeks were plotted and summarized according to dose to visually assess dose-related changes.

\section{Post Hoc Analyses}

Demographic and baseline characteristics were compared among treatment groups with the use of the chi-square test or Fisher's exact test for categorical variables and analysis of variance with van der Waerden normal scores for continuous variables.

The prespecified analysis of the primary end point and related efficacy end points was the assessment of dose response with the use of an $\mathrm{E}_{\mathrm{MAX}}$ model. Here we report between-group comparisons; thus, we used the Cochran-Mantel-Haenszel chi-square test with stratification according to prior anti-TNF therapy. This analysis was based on data for all patients receiving at least one dose 
of study medication. Patients with missing data were considered to be nonresponders. No adjustments were made for multiple comparisons. A sensitivity analysis was conducted for clinical response, in which patients receiving placebo withdrawn for reasons not related to treatment were considered to be responders in a "worstcase-scenario" approach.

To compare the consistency of the effect of study treatment on clinical response with placebo and with tofacitinib at a dose of $0.5 \mathrm{mg}, 3 \mathrm{mg}$, $10 \mathrm{mg}$, or $15 \mathrm{mg}$ twice daily, we performed one prespecified subgroup analysis (according to prior use or nonuse of anti-TNF therapy) as well as multiple post hoc subgroup analyses (according to sex, age, weight, body-mass index, duration of ulcerative colitis, colonic area involved, baseline total Mayo score, CRP concentration at baseline, baseline fecal calprotectin concentration, and glucocorticoid and mesalamine use at baseline) were performed. The heterogeneity of treatment effect was assessed with the use of a BreslowDay test. The incidence of adverse events was analyzed by means of Fisher's exact test.

We calculated that a total of 180 patients would need to be enrolled and have data that could be evaluated in order for the study to have $80 \%$ power to detect a relative difference of $20 \%$ in the rate of the primary end point of clinical response at 8 weeks between the group receiving placebo - assuming a rate of $35 \%$ in this group - and the group receiving tofacitinib at a dose of $15 \mathrm{mg}$ twice daily, at the one-sided 5\% significance level. This calculation was based on a simulation study in which the simulated data were analyzed using a three-parameter $\mathrm{E}_{\mathrm{MAX}}$ model. On this basis, we aimed to enroll 45 patients in the placebo group and in the 15-mg twice-daily tofacitinib group and 30 patients in each of the other tofacitinib groups (receiving $0.5 \mathrm{mg}, 3 \mathrm{mg}$, and $10 \mathrm{mg}$ twice daily).

\section{RESULTS}

\section{PATIENT CHARACTERISTICS}

A total of 195 patients were randomly assigned to a study group, of whom 194 received a dose of the study drug: 48 patients in the placebo group and $31,33,33$, and 49 in the tofacitinib groups receiving $0.5 \mathrm{mg}, 3 \mathrm{mg}, 10 \mathrm{mg}$, and $15 \mathrm{mg}$ twice daily, respectively. One patient in the placebo group did not receive the study drug and was excluded from the analyses. The demographic and baseline disease characteristics were similar across the five groups (Table 1), with significant differences $(\mathrm{P}<0.05)$ only in glucocorticoid use at baseline. A total of 157 of the 194 patients (80.9\%) completed the 8-week trial (Fig. 1 in the Supplementary Appendix). Concomitant drug therapy was used in $46,31,33,32$, and 47 patients in the placebo group and the $0.5-\mathrm{mg}, 3-\mathrm{mg}, 10-\mathrm{mg}$, and $15-\mathrm{mg}$ tofacitinib groups, respectively. Across all treatment groups, $131(67.5 \%)$ patients received concomitant aminosalicylates and $85(43.8 \%)$ received concomitant glucocorticoids at some point during the study.

\section{EFFICACY}

\section{Primary End Point}

A clinical response at 8 weeks occurred in 20 of 48 patients $(42 \%)$ receiving placebo $(95 \%$ confidence interval [CI], 28 to 56), as compared with 10 of $31(32 \%)$ receiving $0.5 \mathrm{mg}$ of tofacitinib (95\% CI, 16 to 49; $\mathrm{P}=0.39$ ), 16 of 33 (48\%) receiving $3 \mathrm{mg}$ of tofacitinib (95\% CI, 31 to $66 ; \mathrm{P}=0.55$ ), 20 of $33(61 \%)$ receiving $10 \mathrm{mg}$ of tofacitinib (95\% CI, 44 to $77 ; \mathrm{P}=0.10$ ), and 38 of 49 (78\%) receiving $15 \mathrm{mg}$ of tofacitinib (95\% CI, 66 to 89; $\mathrm{P}<0.001$ ) (Fig. 1A). The results of the prespecified statistical analysis for the clinical response (Table 2 in the Supplementary Appendix) and the sensitivity analysis for clinical response (Fig. 2 in the Supplementary Appendix) are consistent with these findings. The efficacy of tofacitinib at doses of $10 \mathrm{mg}$ and $15 \mathrm{mg}$ twice daily was generally consistent among demographic subgroups and subgroups according to baseline disease characteristics; however, caution should be used in the interpretation of subgroup analyses owing to the limitations of multiple comparisons and small sample sizes (Fig. $4 \mathrm{~A}$ and $4 \mathrm{~B}$ in the Supplementary Appendix).

\section{Secondary End Points}

Clinical remission at 8 weeks occurred in 5 of 48 patients (10\%) receiving placebo ( $95 \%$ CI, 2 to 19$)$, as compared with 4 of $31(13 \%)$ receiving $0.5 \mathrm{mg}$ of tofacitinib (95\% CI, 1 to $25 ; \mathrm{P}=0.76$ ), 11 of 33 (33\%) receiving $3 \mathrm{mg}$ of tofacitinib $(95 \% \mathrm{CI}, 17$ to 49 ; $\mathrm{P}=0.01), 16$ of 33 (48\%) receiving $10 \mathrm{mg}$ of tofacitinib ( $95 \% \mathrm{CI}, 31$ to $66 ; \mathrm{P}<0.001$ ), and 20 of 49 (41\%) receiving $15 \mathrm{mg}$ of tofacitinib $(95 \% \mathrm{CI}$, 27 to 55 ; $\mathrm{P}<0.001$ ) (Fig. 1B).

An endoscopic response at 8 weeks occurred 


\begin{tabular}{|c|c|c|c|c|c|c|}
\hline \multirow[t]{2}{*}{ Characteristic } & \multirow[t]{2}{*}{$\begin{array}{l}\text { Placebo } \\
(\mathrm{N}=48)\end{array}$} & \multicolumn{4}{|c|}{ Tofacitinib } & \multirow[t]{2}{*}{ P Value } \\
\hline & & $\begin{array}{c}0.5 \mathrm{mg} \\
(\mathrm{N}=31)\end{array}$ & $\begin{array}{c}3 \mathrm{mg} \\
(\mathrm{N}=33)\end{array}$ & $\begin{array}{c}10 \mathrm{mg} \\
(\mathrm{N}=33)\end{array}$ & $\begin{array}{c}15 \mathrm{mg} \\
(\mathrm{N}=49)\end{array}$ & \\
\hline Male sex — no. (\%) & $23(48)$ & $17(55)$ & $19(58)$ & $21(64)$ & $26(53)$ & 0.71 \\
\hline White race - no. $(\%) \ddagger$ & $43(90)$ & $28(90)$ & $30(91)$ & $30(91)$ & $45(92)$ & 1.00 \\
\hline Age $-y r$ & $42.5 \pm 14.7$ & $43.8 \pm 13.4$ & $42.5 \pm 14.3$ & $43.2 \pm 12.8$ & $41.2 \pm 13.5$ & 0.92 \\
\hline Body weight — kg & $74.6 \pm 15.8$ & $75.6 \pm 13.3$ & $73.8 \pm 16.4$ & $75.9 \pm 13.2$ & $74.1 \pm 17.7$ & 0.89 \\
\hline Body-mass index $\mathbb{J}$ & $25.3 \pm 4.0$ & $26.3 \pm 3.7$ & $24.8 \pm 3.9$ & $25.4 \pm 4.0$ & $25.6 \pm 5.2$ & 0.61 \\
\hline Smoking status - no./total no. (\%) & & & & & & 0.52 \\
\hline Never smoker & $34 / 48(71)$ & $16 / 31(52)$ & $19 / 33(58)$ & $24 / 32(75)$ & $34 / 49(69)$ & \\
\hline Smoker & $2 / 48(4)$ & $3 / 31(10)$ & $4 / 33(12)$ & $1 / 32(3)$ & $4 / 49(8)$ & \\
\hline Former smoker & $12 / 48(25)$ & $12 / 31(39)$ & $10 / 33(30)$ & $7 / 32(22)$ & $11 / 49(22)$ & \\
\hline Disease duration $-\mathrm{yr}$ & $8.8 \pm 5.4$ & $8.8 \pm 9.1$ & $8.9 \pm 8.8$ & $10.9 \pm 6.6$ & $7.6 \pm 5.7$ & 0.47 \\
\hline Involved colonic area - no./total no. (\%) & & & & & & 0.56 \\
\hline Rectosigmoid & $14 / 46(30)$ & $13 / 30(43)$ & $9 / 32(28)$ & $7 / 31(23)$ & $18 / 46(39)$ & \\
\hline Left-sided & $12 / 46(26)$ & $8 / 30(27)$ & $11 / 32(34)$ & $11 / 31(35)$ & $11 / 46(24)$ & \\
\hline Extensive & $20 / 46(43)$ & $9 / 30(30)$ & $12 / 32(38)$ & $13 / 31(42)$ & $17 / 46(37)$ & \\
\hline $\mathrm{CRP}(\mathrm{mg} /$ liter $) 9$ & & & & & & 0.66 \\
\hline Mean \pm SD & $9.7 \pm 12.8$ & $18.8 \pm 29.4$ & $12.6 \pm 13.2$ & $11.3 \pm 16.5$ & $17.1 \pm 26.4$ & \\
\hline Range & $0.2-61.2$ & $0.4-118.0$ & $0.2-55.5$ & $0.2-72.4$ & $0.2-124.0$ & \\
\hline Elevated CRP — no./total no. (\%) 9 & $34 / 48(71)$ & $21 / 31(68)$ & $22 / 33(67)$ & $22 / 32(69)$ & $34 / 49(69)$ & 0.99 \\
\hline \multicolumn{7}{|l|}{ Fecal calprotectin $(\mathrm{mg} / \mathrm{kg})$} \\
\hline Mean \pm SD & $1733 \pm 2596$ & $1440 \pm 1623$ & $1474 \pm 2182$ & $1145 \pm 2001$ & $1523 \pm 2575$ & 0.49 \\
\hline Range & $28-10,617$ & $28-5919$ & $28-9134$ & $28-10,485$ & $28-13,590$ & \\
\hline Mayo score $\|$ & $8.2 \pm 1.6$ & $8.6 \pm 1.6$ & $8.3 \pm 1.5$ & $8.0 \pm 1.7$ & $8.0 \pm 1.5$ & 0.38 \\
\hline Mesalamine use at baseline - no. (\%) & $29(60)$ & $16(52)$ & $19(58)$ & $25(76)$ & $33(67)$ & 0.29 \\
\hline Glucocorticoid use at baseline - no. (\%) & $13(27)$ & $11(35)$ & $10(30)$ & $19(58)$ & $13(27)$ & 0.03 \\
\hline $\begin{array}{l}\text { Glucocorticoid failure within } \\
\text { previous } 12 \text { mo - no. (\%) }\end{array}$ & $15(31)$ & $12(39)$ & $8(24)$ & $5(15)$ & $13(27)$ & 0.28 \\
\hline Anti-TNF exposure - no. (\%) & $15(31)$ & $9(29)$ & $10(30)$ & $10(30)$ & $15(31)$ & 0.81 \\
\hline $\begin{array}{l}\text { Anti-TNF failure within previous } \\
12 \mathrm{mo}-\text { no. (\%) }\end{array}$ & $12(25)$ & $2(6)$ & $6(18)$ & $6(18)$ & $10(20)$ & 0.35 \\
\hline $\begin{array}{l}\text { Immunosuppressant failure within } \\
\text { previous } 12 \mathrm{mo}-\text { no. }(\%)^{* * *}\end{array}$ & $20(42)$ & $13(42)$ & $12(36)$ & $16(48)$ & $18(37)$ & 0.84 \\
\hline \multicolumn{7}{|c|}{$\begin{array}{l}\text { Plus-minus values are means } \pm \text { SD. CRP denotes C-reactive protein, and TNF tumor necrosis factor } \\
\mathrm{P} \text { values are based on global tests to assess heterogeneity among treatment groups. Values for all } \\
\text { ables are based on a two-sided chi-square test or Fisher's exact test. P values for continuous variab } \\
\text { analysis of variance of the van der Waerden normal scores. } \\
\text { Race was self-reported. } \\
\text { The body-mass index is the weight in kilograms divided by the square of the height in meters. } \\
\text { The normal range for CRP is } 0 \text { to } 3 \mathrm{mg} \text { per liter. } \\
\text { The Mayo score can range from } 0 \text { to } 12 \text { points, with higher scores indicating more severe disease. } \\
\text { * Immunosuppressant agents include azathioprine, } 6 \text {-mercaptopurine, and methotrexate. }\end{array}$} \\
\hline
\end{tabular}

in 22 of 48 patients $(46 \%)$ receiving placebo, as $3 \mathrm{mg}$ of tofacitinib $(\mathrm{P}=0.30), 22$ of $33(67 \%)$ recompared with 16 of $31(52 \%)$ receiving $0.5 \mathrm{mg}$ ceiving $10 \mathrm{mg}$ of tofacitinib ( $\mathrm{P}=0.07)$, and 38 of of tofacitinib ( $\mathrm{P}=0.64), 19$ of $33(58 \%)$ receiving $49(78 \%)$ receiving $15 \mathrm{mg}$ of tofacitinib $(\mathrm{P}=0.001)$ 


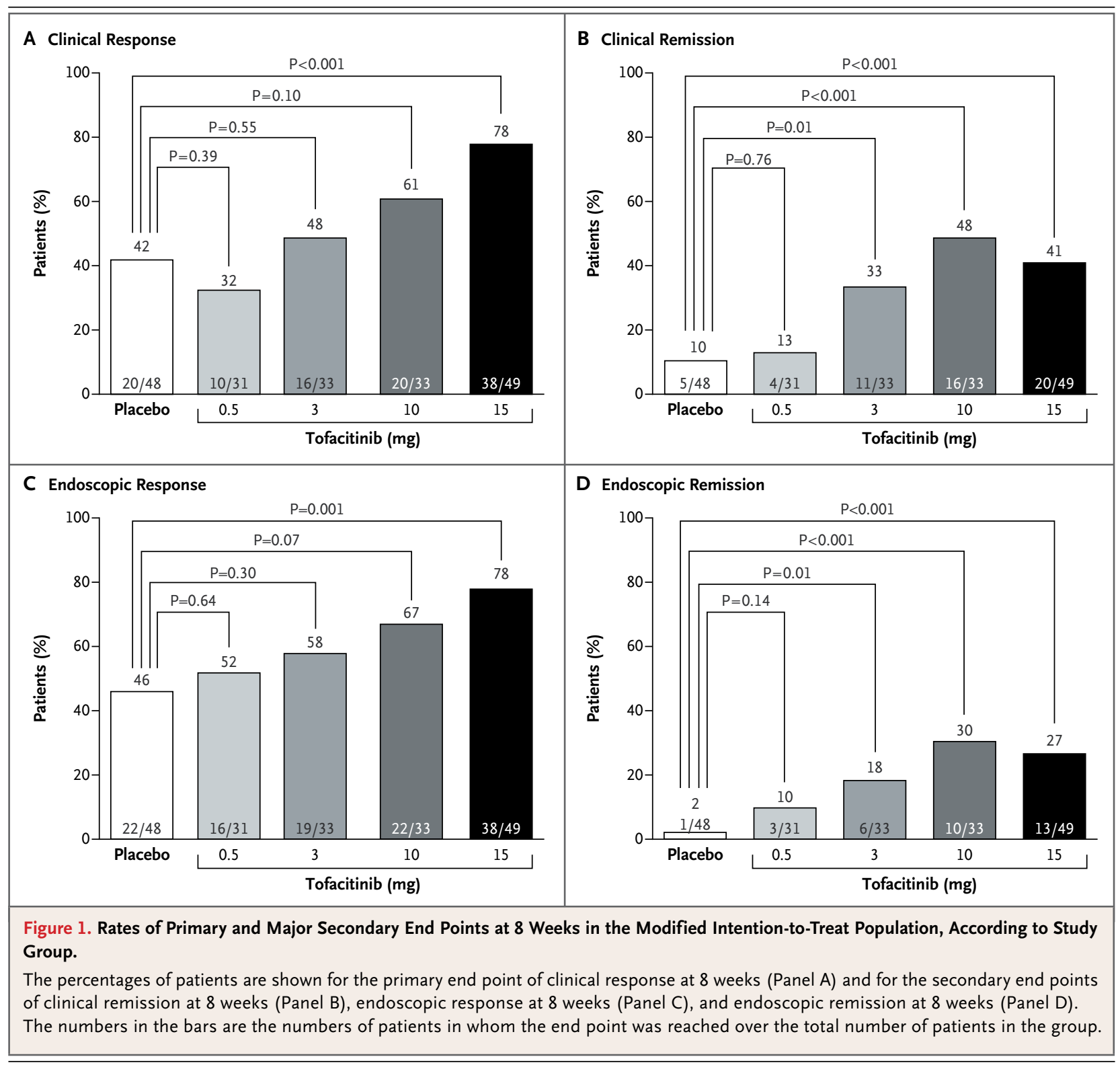

(Fig. 1C). Endoscopic remission at 8 weeks occurred in 1 of 48 patients (2\%) receiving placebo, as compared with 3 of $31(10 \%)$ receiving $0.5 \mathrm{mg}$ of tofacitinib ( $\mathrm{P}=0.14), 6$ of $33(18 \%)$ receiving $0.5 \mathrm{mg}$ of tofacitinib $(\mathrm{P}=0.01), 10$ of $33(30 \%)$ receiving $10 \mathrm{mg}$ of tofacitinib ( $\mathrm{P}<0.001)$, and 13 of $49(27 \%)$ receiving $15 \mathrm{mg}$ of tofacitinib $(\mathrm{P}<0.001)$ (Fig. 1D).

The mean total Mayo scores, mean partial Mayo scores, mean Inflammatory Bowel Disease Questionnaire scores, mean CRP concentrations, and mean fecal calprotectin concentrations during the study period are shown in Figure 2 (and in Fig. 3 in the Supplementary Appendix).

\section{SAFETY}

The most commonly reported adverse events related to infection were influenza and nasopharyngitis (in six patients each) (Table 2). Two patients receiving $10 \mathrm{mg}$ of tofacitinib twice daily had serious adverse events from infection (postoperative abscess in one and anal abscess in the other). There was a dose-dependent increase in both LDL and HDL cholesterol concentrations at 8 weeks with tofacitinib, which reversed after discontinuation of the study drug (Tables 1 and 3 in the Supplementary Appendix). During the study period, the absolute neutrophil count was less than 1500 cells per cubic millimeter in three patients 


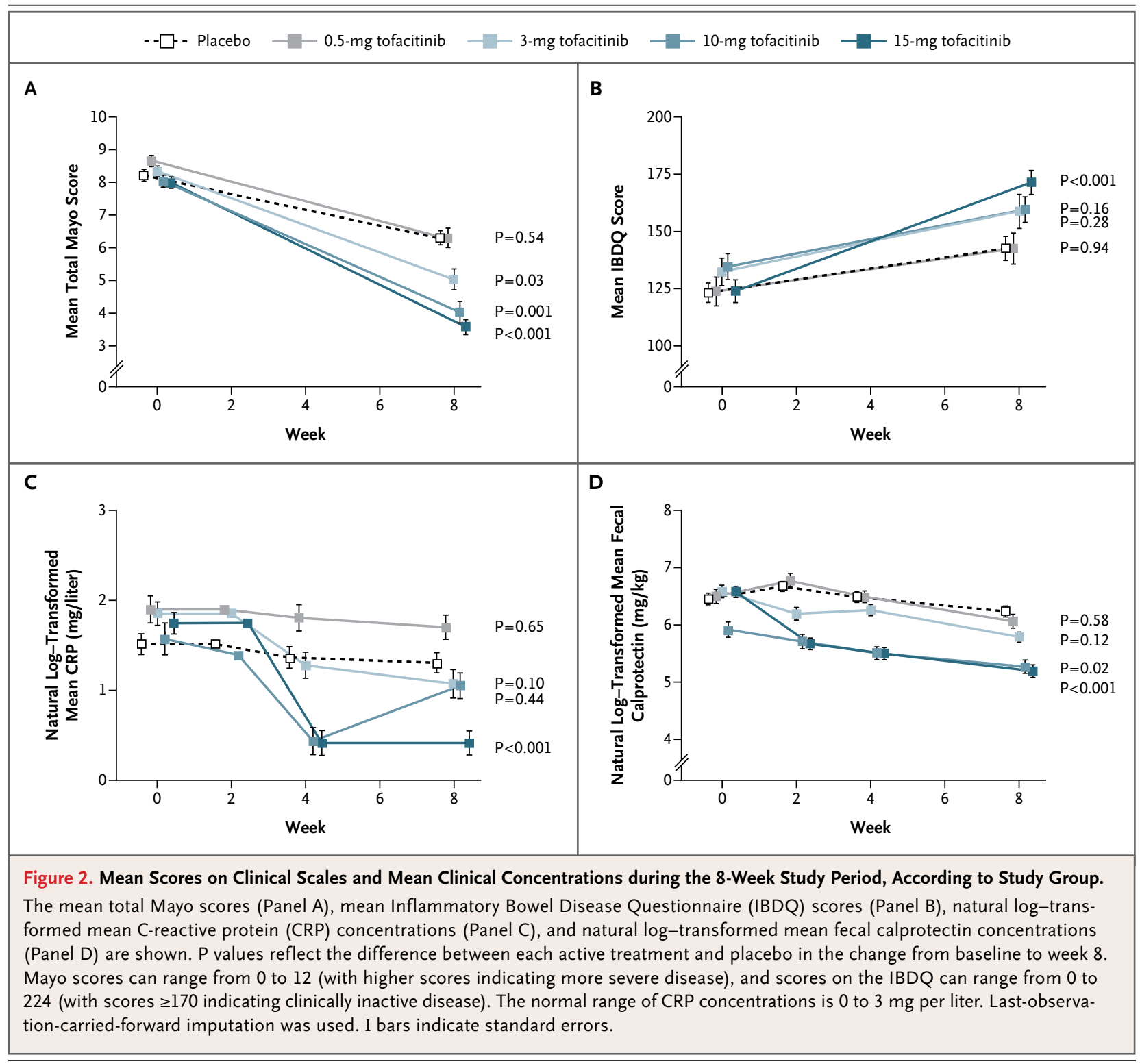

receiving tofacitinib (one at a dose of $10 \mathrm{mg}$ twice daily and two at a dose of $15 \mathrm{mg}$ twice daily); it was less than 1000 cells per cubic millimeter in none of the patients.

\section{I SCUSSION}

In this 8-week phase 2 trial of patients with moderately or severely active ulcerative colitis, in most of whom conventional therapy (mesalamine, glucocorticoids, immunosuppressants, or anti-TNF agents or a combination thereof) had failed, the highest dose of tofacitinib (15 mg twice daily) achieved significant improvements in the prima- ry outcome of induction of a clinical response and in the secondary outcomes of clinical remission and endoscopic response and remission. The 10-mg twice-daily dose achieved significant improvements in most secondary outcomes. In addition, tofacitinib administration resulted in a reduction of CRP and fecal calprotectin concentrations and improvements in the Inflammatory Bowel Disease Questionnaire score. The efficacy of tofacitinib as maintenance therapy for ulcerative colitis is unknown.

We required patients receiving azathioprine, 6-mercaptopurine, and methotrexate to discontinue them immediately before initiating therapy 


\begin{tabular}{|c|c|c|c|c|c|c|}
\hline \multirow[t]{2}{*}{ Characteristic } & \multirow[t]{2}{*}{$\begin{array}{l}\text { Placebo } \\
(\mathrm{N}=48)\end{array}$} & \multicolumn{4}{|c|}{ Tofacitinib } & \multirow[t]{2}{*}{ P Value } \\
\hline & & $\begin{array}{l}0.5 \mathrm{mg} \\
(\mathrm{N}=31)\end{array}$ & $\begin{array}{c}3 \mathrm{mg} \\
(\mathrm{N}=33)\end{array}$ & $\begin{array}{l}10 \mathrm{mg} \\
(\mathrm{N}=33)\end{array}$ & $\begin{array}{l}15 \mathrm{mg} \\
(\mathrm{N}=49)\end{array}$ & \\
\hline No. of adverse events & 46 & 34 & 20 & 37 & 41 & \\
\hline Serious adverse events — no. of patients $(\%) \ddagger$ & $4(8)$ & $1(3)$ & $1(3)$ & $2(6)$ & $2(4)$ & 0.47 \\
\hline $\begin{array}{l}\text { Serious adverse events from infection - no. of } \\
\text { patients }(\%) \dagger\end{array}$ & 0 & 0 & 0 & $2(6)$ & 0 & \\
\hline Adverse events — no. of patients (\%) & $23(48)$ & $19(61)$ & $11(33)$ & $14(42)$ & $20(41)$ & 0.74 \\
\hline \multicolumn{7}{|l|}{$\begin{array}{l}\text { Adverse events occurring in } \geq 5 \% \text { of patients in any } \\
\text { tofacitinib group - no. (\%) } \int\end{array}$} \\
\hline Abdominal pain & $1(2)$ & $1(3)$ & 0 & 0 & $3(6)$ & \\
\hline Ulcerative colitis & 9 (19) & $5(16)$ & $3(9)$ & $2(6)$ & $3(6)$ & \\
\hline Dyspepsia & 0 & $2(6)$ & $1(3)$ & 0 & 0 & \\
\hline Influenza & $3(6)$ & $2(6)$ & 0 & 0 & $1(2)$ & \\
\hline Nasopharyngitis & $1(2)$ & $2(6)$ & $1(3)$ & $1(3)$ & $1(2)$ & \\
\hline Sinusitis & 0 & $2(6)$ & 0 & 0 & 0 & \\
\hline Arthralgia & 0 & 0 & 0 & $2(6)$ & $2(4)$ & \\
\hline Pain in extremity & 0 & $1(3)$ & 0 & $2(6)$ & 0 & \\
\hline Dizziness & $1(2)$ & $2(6)$ & 0 & $1(3)$ & $2(4)$ & \\
\hline Headache & $2(4)$ & $2(6)$ & $3(9)$ & $3(9)$ & $4(8)$ & \\
\hline Rash & 0 & 0 & $2(6)$ & $1(3)$ & 0 & \\
\hline $\begin{array}{l}\text { Adverse events leading to study-drug discontinuation } \\
\qquad- \text { no. of patients (\%) }\end{array}$ & $4(8)$ & $2(6)$ & 0 & $1(3)$ & $2(4)$ & 0.37 \\
\hline Adverse events from infection - no. of patients (\%) & $7(15)$ & $8(26)$ & $3(9)$ & $9(27)$ & $3(6)$ & 1.00 \\
\hline Change in LDL cholesterol from baseline - $\mathrm{mg} / \mathrm{d} \mid q$ & $-3.5 \pm 21.3$ & $10.7 \pm 37.8$ & $-0.7 \pm 15.6$ & $-5.8 \pm 21.8$ & $1.5 \pm 19.3$ & \\
\hline Change in HDL cholesterol from baseline $-\mathrm{mg} / \mathrm{dl} \|$ & $1.9 \pm 10.1$ & $4.5 \pm 12.7$ & $3.0 \pm 9.9$ & $0.9 \pm 15.0$ & $0.9 \pm 14.7$ & \\
\hline
\end{tabular}

* Plus-minus values are means \pm SD. Twenty of 31 patients (65\%), 26 of 33 (79\%), 31 of 33 (94\%), and 45 of 49 (92\%) in the $0.5-\mathrm{mg}, 3-\mathrm{mg}, 10-\mathrm{mg}$, and $15-\mathrm{mg}$ tofacitinib groups, respectively, and 35 of 48 patients $(73 \%)$ in the placebo group completed the study and had safety data after 8 weeks, unless otherwise indicated.

$\uparrow P$ values are based on Fisher's exact test for the comparison of the combined tofacitinib groups with placebo group.

$\$$ The protocol definition of a serious adverse event is any untoward medical occurrence at any dose that results in death, is life-threatening (has an immediate risk of death), requires admission to a hospital or prolongation of existing hospitalization, results in persistent or significant disability or incapacity, or results in a congenital anomaly or birth defect. $\int$ See the Supplementary Appendix for an expanded version of this table that includes adverse events occurring in more than $1 \%$ of patients in any tofacitinib group and clinical laboratory test data.

9 For low-density lipoprotein (LDL) cholesterol, data at 12 weeks were available for 28 of 31 patients (90\%), 28 of 33 (85\%), 30 of $33(91 \%)$, and 47 of $49(96 \%)$ in the $0.5-\mathrm{mg}, 3-\mathrm{mg}, 10-\mathrm{mg}$, and 15-mg tofacitinib groups, respectively, and for 43 of 48 patients (90\%) in the placebo group.

|| For high-density lipoprotein (HDL) cholesterol, data at 12 weeks were available for 28 of 31 patients (90\%), 28 of 33 $(85 \%), 31$ of $33(94 \%)$, and 47 of $49(96 \%)$ in the $0.5-\mathrm{mg}, 3-\mathrm{mg}, 10-\mathrm{mg}$, and 15-mg tofacitinib groups, respectively, and for 43 of 48 patients $(90 \%)$ in the placebo group.

with tofacitinib, and patients who had previously received anti-TNF therapy were required to discontinue it for at least 8 weeks before study entry. Thus, the results cannot be extrapolated to patients who do not discontinue those agents before treatment with tofacitinib.

In our previous small, 4-week phase 2a trial of tofacitinib at doses of $1 \mathrm{mg}, 5 \mathrm{mg}$, and $15 \mathrm{mg}$ twice daily in patients with moderate or severe Crohn's disease, there were high rates of response and remission and no evidence of significant clinical efficacy with tofacitinib. ${ }^{25}$ Whether the failure of tofacitinib for the clinical efficacy end points in Crohn's disease represents a real difference from ulcerative colitis in the effect of tofacitinib is unclear. 
Tofacitinib treatment resulted in an increase in LDL and HDL cholesterol levels; however, the small size and short duration of the trial did not allow for a comprehensive assessment of the safety and tolerability of the drug in patients with ulcerative colitis. In patients with rheumatoid arthritis, tofacitinib has been associated with increases in LDL cholesterol and serum creatinine concentrations and decreases in the absolute neutrophil count; and the 15-mg twice-daily dose has been associated with an increased risk of infection. In the current study, we observed three cases in which the absolute neutrophil count decreased to less than 1500 per cubic millimeter and a dosedependent increase in both LDL and HDL cholesterol concentrations but not an increase in aspar- tate aminotransferase, alanine aminotransferase, or serum creatinine concentrations or a decrease in serum hemoglobin concentration. The mechanism for the alterations in cholesterol profile is unknown. The clinical consequences of these laboratory abnormalities require further study.

In conclusion, patients with moderately or severely active ulcerative colitis treated with tofacitinib had a clinical response and clinical remission more frequently than those receiving placebo.

Supported by Pfizer.

Disclosure forms provided by the authors are available with the full text of this article at NEJM.org.

We thank the patients who were involved in this study; the A3921063 investigators and study team, including Bernita Davies, Kawleen Oberoi, and Jacqui Spanton; and Martin Goulding, Ph.D., at Complete Medical Communications for editorial support (funded by Pfizer).
REFERENCES

1. Baumgart DC, Carding SR. Inflammatory bowel disease: cause and immunobiology. Lancet 2007;369:1627-40.

2. Baumgart DC, Sandborn WJ. Inflammatory bowel disease: clinical aspects and established and evolving therapies. Lancet 2007;369:1641-57.

3. Langholz E, Munkholm P, Davidsen M, Binder V. Course of ulcerative colitis: analysis of changes in disease activity over years. Gastroenterology 1994;107:3-11. 4. Kornbluth A, Sachar DB. Ulcerative colitis practice guidelines in adults: American College of Gastroenterology, Practice Parameters Committee. Am J Gastroenterol 2010;105:501-23. [Erratum, Am J Gastroenterol 2010;103:500.]

5. Reinisch W, Sandborn WJ, Hommes DW, et al. Adalimumab for induction of clinical remission in moderately to severely active ulcerative colitis: results of a randomised controlled trial. Gut 2011;60: 780-7.

6. Travis SP, Stange EF, Lémann M, et al. European evidence-based consensus on the management of ulcerative colitis: current management. J Crohns Colitis 2008; 2:24-62.

7. Lichtenstein GR, Abreu MT, Cohen R, Tremaine W. American Gastroenterological Association Institute technical review on corticosteroids, immunomodulators, and infliximab in inflammatory bowel disease. Gastroenterology 2006;130:940-87. 8. Changelian PS, Moshinsky D, Kuhn $\mathrm{CF}$, et al. The specificity of JAK3 kinase inhibitors. Blood 2008;111:2155-7. [Erratum, Blood 2009;114:3132.]

9. Flanagan ME, Blumenkopf TA, Brissette WH, et al. Discovery of CP-690,550: a potent and selective Janus kinase (JAK) inhibitor for the treatment of autoimmune diseases and organ transplant rejection. J Med Chem 2010;53:8468-84.
10. Ghoreschi K, Jesson MI, Li X, et al. Modulation of innate and adaptive immune responses by tofacitinib (CP-690, 550). J Immunol 2011;186:4234-43.

11. Meyer DM, Jesson MI, Li X, et al. Antiinflammatory activity and neutrophil reductions mediated by the JAK1/JAK3 inhibitor, CP-690,550, in rat adjuvantinduced arthritis. J Inflamm (Lond) 2010; 7:41.

12. Sewgobind VD, Quaedackers ME, van der Laan LJ, et al. The Jak inhibitor CP690,550 preserves the function of CD4CD25FoxP3 regulatory $\mathrm{T}$ cells and inhibits effector T cells. Am J Transplant 2010;10:1785-95.

13. Changelian PS, Flanagan ME, Ball DJ, et al. Prevention of organ allograft rejection by a specific Janus kinase 3 inhibitor. Science 2003;302:875-8.

14. Vincenti F, Tedesco Silva H, Busque $S$, et al. Randomized phase $2 \mathrm{~b}$ trial of tofacitinib (CP-690,550) in de novo kidney transplant patients: efficacy, renal function and safety at 1 year. Am J Transplant 2012 June 8 (Epub ahead of print).

15. Kremer JM, Bloom BJ, Breedveld FC et al. The safety and efficacy of a JAK inhibitor in patients with active rheumatoid arthritis: results of a double-blind, placebo-controlled phase IIa trial of three dose levels of CP-690,550 versus placebo. Arthritis Rheum 2009;60:1895-905.

16. Tanaka Y, Suzuki M, Nakamura $H$ Toyoizumi S, Zwillich SH. Phase II study of tofacitinib (CP-690,550) combined with methotrexate in patients with rheumatoid arthritis and an inadequate response to methotrexate. Arthritis Care Res (Hoboken) 2011;63:1150-8.

17. van Vollenhoven RF, Fleischmann $R$, Cohen S, et al. Tofacitinib or adalimumab versus placebo in rheumatoid arthritis. N Engl J Med 2012;367:508-19.
18. Fleischmann R, Kremer J, Cush J, et al. Placebo-controlled trial of tofacitinib monotherapy in rheumatoid arthritis. N Engl J Med 2012;367:495-507.

19. Boy MG, Wang C, Wilkinson BE, et al. Double-blind, placebo-controlled, doseescalation study to evaluate the pharmacologic effect of CP-690,550 in patients with psoriasis. J Invest Dermatol 2009; 129:2299-302.

20. Papp K, Menter A, Strober B, et al. Efficacy and safety of tofacitinib, an oral JAK inhibitor, in the treatment of psoriasis: a phase $2 \mathrm{~b}$ randomised placebo-controlled dose-ranging study. Br J Dermatol (in press).

21. Schroeder KW, Tremaine WJ, Ilstrup DM. Coated oral 5-aminosalicylic acid therapy for mildly to moderately active ulcerative colitis - a randomized study. N Engl J Med 1987;317:1625-9.

22. Rutgeerts P, Sandborn WJ, Feagan $\mathrm{BG}$, et al. Infliximab for induction and maintenance therapy for ulcerative colitis. N Engl J Med 2005;353:2462-76. [Erratum, N Engl J Med 2006;354:2200.]

23. D'Haens G, Sandborn WJ, Feagan BG, et al. A review of activity indices and efficacy end points for clinical trials of medical therapy in adults with ulcerative colitis. Gastroenterology 2007;132:763-86. 24. Irvine EJ, Feagan B, Rochon J, et al. Quality of life: a valid and reliable measure of therapeutic efficacy in the treatment of inflammatory bowel disease. Gastroenterology 1994;106:287-96.

25. Sandborn WJ, Ghosh S, Panes J, Vranic I, Spanton J, Niezychowski W. Phase 2 randomized study of CP-690,550, an oral Janus kinase inhibitor, in active Crohn's disease. Gastroenterology 2011; 140:Suppl:S124. abstract.

Copyright (c) 2012 Massachusetts Medical Society. 